\title{
Perspectives of South African general surgeons regarding their postgraduate training
}

\author{
M M de Beer, MB ChB, MMed (Surg); V O L Karusseit, MB ChB, MFGP (SA), MMed (Surg), FCS (SA); \\ B H Pienaar, MB ChB, FRCS (Glasg), ChM \\ Department of Surgery, School of Medicine, Faculty of Health Sciences, University of Pretoria and Steve Biko \\ Academic Hospital, Pretoria, South Africa
}

Corresponding author: V O L Karusseit (otto.karusseit@up.ac.za)

\begin{abstract}
Background. There is a perception among general surgeons that there are deficiencies in surgical training in South Africa (SA). Dependence on under-resourced state training institutions possibly plays a role. The opinions of qualified surgeons may make an invaluable contribution in this regard.

Objectives. To canvass the perceptions of SA general surgeons regarding certain aspects of their training.

Methods. An electronic postal survey was conducted. All general surgeons on the Association of Surgeons of South Africa database were requested to complete a structured questionnaire. Four Likert scale items were interrogated: knowledge acquisition, surgical skill, research, and practice management.

Results. Eighty-eight surgeons responded. Knowledge acquisition and surgical skills development were regarded positively, except for a perceived deficiency in availability of newer technologies. Exposure to surgical research was viewed as beneficial and useful. However, the mandatory research project during training was not perceived as useful for current careers. Training in practice management was perceived as severely deficient.

Conclusion. This survey highlights positive perceptions of general surgeons regarding the acquisition of knowledge and surgical skills during training in SA, but some negative views emerged regarding research, exposure to newer technology, and especially practice management training.
\end{abstract}

S Afr J Surg 2014;52(3):67-71. DOI:10.7196/SAJS.1993

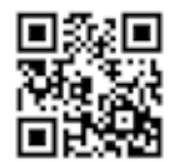

An ever-growing responsibility is placed on training institutions in South Africa (SA) to continue high standards of medical education. The change in the SA government's health policies has resulted in more funding being channelled to primary healthcare, and therefore away from tertiary training centres. ${ }^{[1]}$ Because of the spiralling costs of new technology and pharmaceuticals there is less exposure of trainees to state-ofthe-art medical practice. There is also a reduction of exposure to clinical material because of restrictions on patient care in tertiary institutions.

There is a perception among general surgeons that there are deficiencies in the training in SA. It may be necessary to adapt postgraduate curricula to maintain standards. Qualified surgeons of all eras may be able to make an invaluable contribution in this regard.

\section{Objective}

To canvass the opinions of general surgeons regarding their perception of postgraduate training in SA. A secondary aim was to possibly discern aspects of training that could be improved, with a view to making recommendations.

\section{Methods}

An electronic postal survey was conducted via e-mail. All the general surgeons on the Association of Surgeons of South Africa (ASSA) database were sent an e-mail explaining the study and giving electronic access to a questionnaire.

The questionnaire contained questions on basic demographics as well as aspects regarding the respondent's perception of his/her postgraduate training. The questions addressed theory/academic teaching, surgical technique, research and training for independent practice. Questions were to be answered on a four-point Likert scale, whereby respondents graded aspects of their training from 1 (very positive perceptions regarding quality or quantity, depending on the type of question) to 4 (very negative perceptions). This construction was used to avoid central tendency bias. Table 1 depicts the areas of training and the aspects of each that were interrogated. An example of one of the items in the questionnaire and the accompanying Likert scales is depicted in Fig. 1. Each section included an open-ended question inviting comment regarding the need for improving the specific aspect of training, and the areas in which this was seen to be necessary.

Descriptive data analysis of the distribution of the median of aggregated scores was performed, and inferential statistics were 
Table 1. Areas of training and aspects of each that were interrogated in the questionnaire

1. Theory and academic teaching
Satisfaction with acquisition of theoretical knowledge
Applicabilty of acquired theory
Emphasis on newer literature and research
Need for further training in theory
2. Surgical training
Satisfactory patient exposure
Sufficient theatre experience
Sufficient instruction and supervision in theatre
Exposure to the latest instrumentation
Exposure to the latest operative techniques
Extent of attendance of further training courses after
qualification
3. Research
Emphasis on trainee research
Utility of own research project in interpreting literature
Utility of own research project in preparation for current
career
Extent of engagement in research after qualification
Training for independent practice
Training in financial management
Preparation regarding medical legislation
Need for practice management training outside medicine

used for comparison within groups. Respondents were arbitrarily divided into groups of time periods of qualification: before 1990, 1990 - 2000 and after 2000. The Kruskal-Wallis method was used to compare these groups' perceptions.

\section{Results}

There are 426 surgeons on the ASSA database. The target sample of 88 respondents $(20.6 \%)$ for statistical validity was achieved. Eightyeight per cent of respondents were male and 12\% female. Fiftynine per cent marked English as their first language, 32\% Afrikaans and $8 \%$ various indigenous SA languages.

There were respondents from all the medical schools in SA. The largest proportions were the University of Cape Town (25\%), the University of the Witwatersrand (20\%), Stellenbosch University (15\%), the Nelson Mandela School of Medicine at the University of KwaZulu-Natal (10\%) and the University of Pretoria (9\%). All sectors of medical practice current in SA were represented (Table 1). The largest proportions of respondents were located in Gauteng (34\%) and Limpopo (30\%), with $11 \%$ or less in each of the other nine provinces.

The Likert scores of the four items of enquiry are graphically represented in Figs 2 - 5. Respondents in general had positive

\section{Practice-related needs}

1. Did you receive financial management training during your studies?

\begin{tabular}{|c|c|c|c|}
\hline Not at all & Slight & Good & Excellent \\
\hline 1 & 2 & 3 & 4 \\
\hline
\end{tabular}

\section{To what extent were you adequately prepared} for medical legislation after completion of your degree?

\begin{tabular}{|c|c|c|c|}
\hline Not at all & Slight & Good & Excellent \\
\hline 1 & 2 & 3 & 4 \\
\hline
\end{tabular}

\section{Was there any training given regarding practice management during your training?}

\begin{tabular}{|c|c|c|c|}
\hline Not at all & Rarely & Often & Frequently \\
\hline 1 & 2 & 3 & 4 \\
\hline
\end{tabular}

4. Have you ever felt the need to attend further training outside of medicine in order to run a successful practice?

\begin{tabular}{|c|c|c|c|}
\hline Not at all & Rarely & Often & Frequently \\
\hline 1 & 2 & 3 & 4 \\
\hline
\end{tabular}

Fig. 1. A specimen from the study questionnaire illustrating the format of the questions and the accompanying Likert scale.

\begin{tabular}{|l|r|l|}
\hline Category & Average score* & $\begin{array}{l}\text { Scores 3 } \\
\text { and 4, \% }\end{array}$ \\
\hline Satisfactory & 3.5 & 96 \\
\hline Applicability & 3.22 & 95 \\
\hline $\begin{array}{l}\text { Emphasis on } \\
\text { recent knowledge }\end{array}$ & 2.9 & 75 \\
\hline Subsequent need & 2.44 & 49 \\
\hline
\end{tabular}

Fig. 2. Knowledge acquisition. $\left({ }^{\star}\right.$ Likert scale: $1=$ not at all; $2=$ slight; $3=$ good; 4 = excellent.)

perceptions of the acquisition of knowledge and surgical skill. There was nevertheless a perception of the need for subsequent knowledge acquisition (score 2.44, Fig. 2). Only 56\% of respondents were satisfied that the latest instrumentation had been available during their training (scores 3 and 4, Fig. 3).

The respondents were less positive about research aspects, marking only average scores (Fig. 4). Although there was 


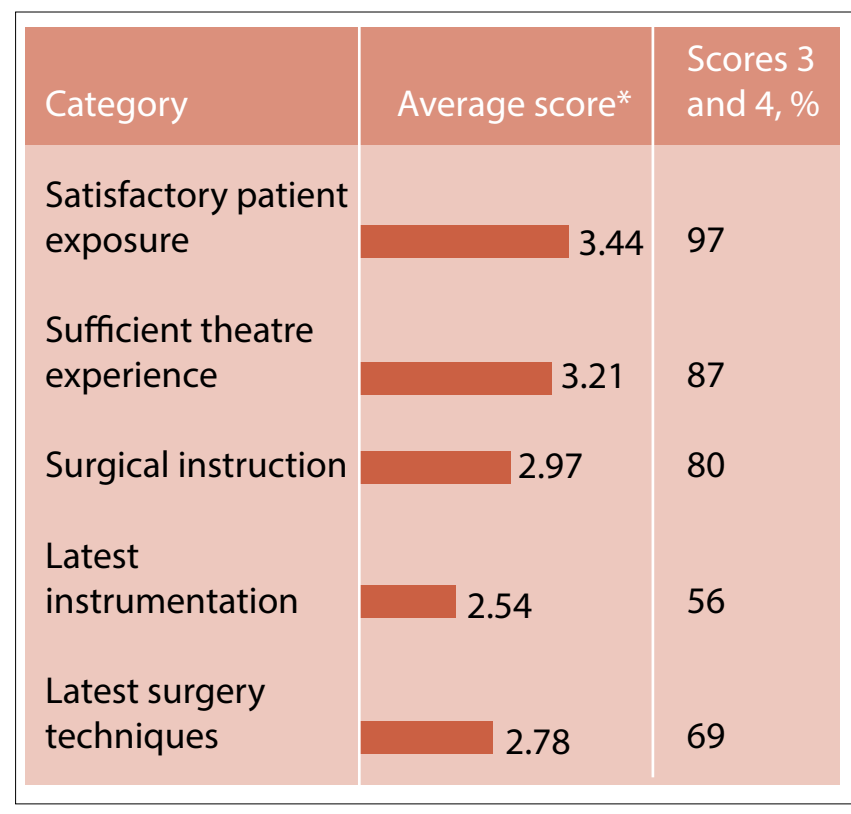

Fig. 3. Practical training. $\left({ }^{*}\right.$ Likert scale: $1=$ not at all; $2=$ slight $3=\operatorname{good} ; 4=$ excellent.)

\begin{tabular}{|l|c|c|}
\hline Category & Average score* & $\begin{array}{l}\text { Scores 3 } \\
\text { and 4, \% }\end{array}$ \\
\hline $\begin{array}{l}\text { Emphasis on } \\
\text { registrar research }\end{array}$ & 2.64 & 66 \\
$\begin{array}{l}\text { Utility in interpreting } \\
\text { literature }\end{array}$ & 2.68 & 59 \\
$\begin{array}{l}\text { Utility of research } \\
\text { project for current } \\
\text { situation }\end{array}$ & 2.27 & 43 \\
\hline $\begin{array}{l}\text { Subsequent research } \\
\text { engagement }\end{array}$ & 2.2 & 37 \\
\hline
\end{tabular}

Fig. 4. Research. $\left({ }^{*}\right.$ Likert scale: $1=$ not at all; $2=$ slight $3=$ good; $4=$ excellent.)

reasonable exposure to and utility of research, only $43 \%$ felt that their own research had been useful for their careers. Only $37 \%$ had engaged in any research after qualification.

There was a negative perception of respondents' preparation for practice management during training (Fig. 5). Scores were very low for education in financial, legislation and practice administration aspects. Seventy-one per cent of respondents felt the need for such training.

Only two comparisons of groups achieved statistical significance. These related to differences in perceptions of surgeons from different time periods of training. These are depicted in Table 3. Surgeons who had qualified after 2000 were less positive

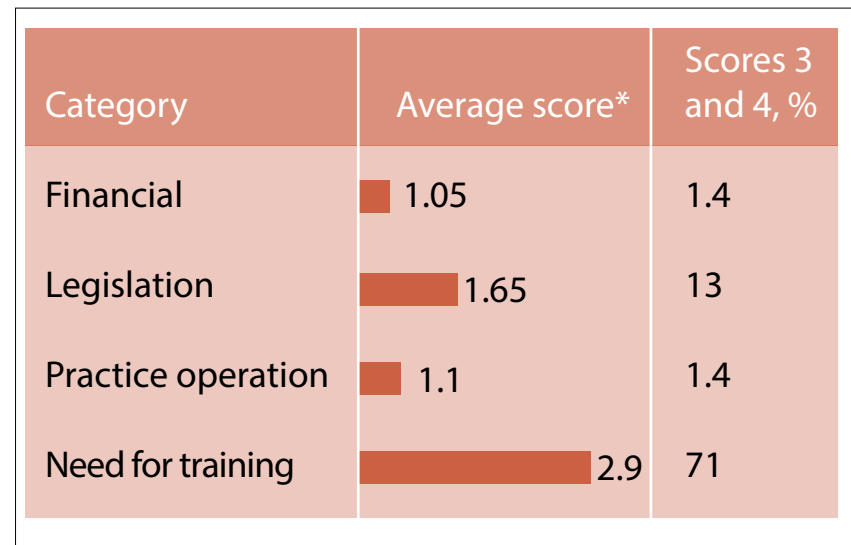

Fig. 5. Training for practice management. $\left({ }^{*}\right.$ Likert scale: $1=$ not at all; $2=$ slight; 3 = good; 4 = excellent.)

Table 2. Sector of practice, $N=88$ respondents

\begin{tabular}{ll}
\hline & $\%$ \\
\hline Private practice & 32 \\
Academic practice & 19 \\
Public hospital and private practice & 14 \\
Academic and private practice & 10 \\
Public hospital & 19 \\
Not answered & 6
\end{tabular}

Table 3. Period of qualification in relation to perceptions of knowledge acquisition and applicability thereof

\begin{tabular}{|c|c|c|}
\hline Period of qualification & $\begin{array}{l}\text { Score, }{ }^{\star} \\
\text { mean }(\mathrm{SD})\end{array}$ & $p$-value \\
\hline \multicolumn{3}{|l|}{ Knowledge acquisition } \\
\hline 1. Pre-1990 & $3.68(0.47)$ & \\
\hline 2. $1990-2000$ & $3.68(0.56)$ & $<0.05^{\dagger}$ \\
\hline 3. Post- 2000 & $3.25(0.57)$ & \\
\hline \multicolumn{3}{|l|}{ Applicability of knowledge } \\
\hline 1. Pre-1990 & $3.50(0.51)$ & \\
\hline 2. $1990-2000$ & $3.22(0.68)$ & $<0.05^{\dagger}$ \\
\hline 3. Post-2000 & $3.03(0.57)$ & \\
\hline $\begin{array}{l}\mathrm{SD}=\text { standard deviation. } \\
{ }^{*} \text { Likert scale: } 1=\text { not at all; } 2= \\
{ }^{\dagger} \text { Group } 1 \text { v. group } 3 \text { (Kruskal- }\end{array}$ & ood; 4 = excellen & \\
\hline
\end{tabular}

about knowledge acquisition during their training than surgeons qualifying before 1990 , scoring 3.25 v. $3.68(p<0.05)$. A similar result was obtained regarding the applicability of knowledge gained to their practice, with scores of 3.03 v. $3.50(p<0.05)$. The same two groups differed in their perception of exposure to the latest surgical techniques and instrumentation (Table 4). Younger surgeons felt that they had had less exposure, scoring 2.37 v. 3.20 $(p<0.01)$ and 2.13 v. $2.95(p<0.01)$, respectively. 


\begin{tabular}{|c|c|c|}
\hline Period of qualification & $\begin{array}{l}\text { Score, }{ }^{\star} \\
\text { mean }(\mathrm{SD})\end{array}$ & $p$-value \\
\hline \multicolumn{3}{|l|}{ Surgical techniques } \\
\hline 1. Pre-1990 & $3.20(0.52)$ & \multirow{3}{*}{$<0.01^{\dagger}$} \\
\hline 2. $1990-2000$ & $2.95(0.57)$ & \\
\hline 3. Post-2000 & $2.37(0.56)$ & \\
\hline \multicolumn{3}{|l|}{ Instrumentation } \\
\hline 1. Pre-1990 & $2.95(0.39)$ & \multirow{3}{*}{$<0.01^{\dagger}$} \\
\hline 2. $1990-2000$ & $2.72(0.45)$ & \\
\hline 3. Post- 2000 & $2.13(0.63)$ & \\
\hline \multicolumn{3}{|c|}{$\mathrm{SD}=$ standard deviation. } \\
\hline \multicolumn{3}{|c|}{${ }^{*}$ Likert scale: $1=$ not at all; $2=$ slight; $3=$ good; $4=$ excellent. } \\
\hline
\end{tabular}

The open-ended questions revealed perceptions of certain deficiencies in the respondents' training (Table 5). It was felt that more education was needed in laparoscopic, oncological and vascular surgery (indicated by 12, 6 and 6, respectively, of 52 respondents). It was also felt that more practical training in laparoscopic and vascular (including endovascular) surgery and in endoscopic techniques was needed (indicated by 36,11 and 5 , respectively, of 45 respondents). The perception of greatest deficiency in training was therefore in laparoscopic (minimally invasive) surgery.

\section{Discussion}

While many surveys have been published of the perceptions of surgical trainees regarding their training, ${ }^{[2]}$ none have canvassed the attitudes of practising surgeons. Gabram et al. ${ }^{[3]}$ canvassed recently graduated surgeons, but addressed only their career concerns and not their training. Our unique survey addresses the surgeon's perceptions after having commenced a career in surgery. The perceived lack of training in business management was therefore not surprising. The survey furthermore reveals some changes in perceptions over time. The perception of deficient exposure to the latest surgical techniques and instrumentation among younger surgeons was not surprising, given the circumstances prevailing in the state health system in SA. The difference in the perception of knowledge acquisition and applicability between older and younger surgeons was, perhaps, less expected.

Training in surgery in SA is based on the traditional FirstWorld model as founded by William Halsted at Johns Hopkins University. ${ }^{[4]}$ Halsted adopted the German 'pyramid' system and introduced a well-defined structured training programme. The conventional surgery training programme is transactional in that knowledge and skills are imparted to registrars by faculty specialists, while caring for patients. Supervision is initially more intense, and responsibility is then gradually passed to the trainee.

In SA this training occurs at state-run public hospitals that are associated with universities and accredited by the Health
Table 5. Common perceptions of deficiencies in education and training

\begin{tabular}{ll}
\hline & $\boldsymbol{n}(\%)$ \\
\hline Theory $(N=52)^{\star}$ & $12(23.1)$ \\
Laparoscopic surgery & $6(11.5)$ \\
Oncological surgery & $6(11.5)$ \\
Vascular surgery & \\
Practical training $(N=45)^{*}$ & $36(80.0)$ \\
Laparoscopic surgery & $11(24.4)$ \\
Vascular (incl. endovascular) surgery & $5(11.1)$ \\
Endoscopic techniques & \\
${ }^{*}$ Not all respondents answered all the open-ended questions. &
\end{tabular}

Professions Council of South Africa. Limited training takes place at private hospitals, usually by consultants who have appointments in academic departments. Concern has previously been expressed by the surgical fraternity regarding the maintenance of high standards of service, teaching and research in SA academic institutions. ${ }^{[5]}$ The dependence on state institutions has serious implications for the training of surgeons. Because of monetary constraints, public healthcare facilities are severely underresourced. This applies to staff, equipment and pharmaceuticals. Restrictions of patient care facilities have limited the exposure of trainees to opportunities to acquire skills.

Perceptions of surgeons regarding laparoscopic training in SA have been surveyed previously. Lack of equipment was identified as a major hurdle to attaining laparoscopic proficiency. ${ }^{[6]}$

The significantly different perceptions in this study regarding knowledge acquisition, and training in the latest surgical techniques/instruments, as perceived by younger compared with older respondents, suggest a deterioration of these aspects over time. While this trend is based solely on perceptions, there is probably some substance bolstering these impressions.

While a greater part of the health budget is justifiably channelled to primary and secondary health care, there is a danger of undermining the viability of the teaching hospitals. ${ }^{[7]}$ These are essential for the training of the professionals required to man the other tiers of medical services.

While salaries for medical staff have improved substantially in recent years in SA, the problems in the public hospitals have made full-time academic practice unattractive. This has limited the recruitment of senior educators and the appointments of junior specialists. Posts for the latter are essential for practice-based learning, and for the development of a career in the public sector. These restrictions on training institutions seem to be reflected in this survey. While surgeons are satisfied with the acquisition of knowledge and skills, there are indications that training hospitals are under-equipped with regard to newer technology. This is indicated by the opinions on laparoscopic, endoscopic and endovascular procedures.

The introduction of a research component by both the universities and the College of Surgeons into training programmes 
in SA is a recent development. The system is still in its infancy and was not viewed positively by respondents. While the emphasis on research was viewed reasonably positively, the required research project was not seen as useful for a surgical career. The emphasis on research in the SA curriculum is somewhat unique. (Performing research is not one of the core competencies stipulated by the Accreditation Council for Graduate Medical Education in the USA. ${ }^{[8]}$ ) The system should probably be nurtured, but is not currently seen as useful by qualified surgeons, the required research project scoring only 2.27 in this survey and only $43 \%$ of surgeons responding positively.

Training in practice management is not included anywhere in any guidelines for postgraduate surgery curricula. It is, however, important for surgeons who enter independent practice. This applies to most SA graduates, and the deficiency in such instruction is seen as a failure of the training. This attitude is abundantly clear in the study findings, perceptions regarding training required in finance, legislation and business management being extremely negative. A vast amount of knowledge of these aspects is required for starting an independent practice in SA.

The lack of training in finance and practice management has been reported previously. Satiani ${ }^{[9]}$ surveyed 133 surgeons and reported that the average surgeon perceived him- or herself to be poorly equipped to understand basic financial principles. This deficiency apparently remains, almost universally, to be rectified ${ }^{[10]}$ The question is, of course, whether such training is the task of the medical school.

The American Surgical Association Blue Ribbon committee recognises changes in the nature of surgical practice and the need for changes in the training of surgeons. ${ }^{[11]}$ It emphasises the need for surgical research during training but makes only broad recommendations. The specific reservations regarding research that are expressed in the present study are not discussed. The need for training in financial and business management is not addressed.

\section{Conclusion}

Responses in this survey from SA general surgeons regarding their training revealed positive perceptions regarding the acquisition of theory and technical skills. The mandatory research component for qualification was negatively perceived, and a different approach, such as more emphasis on translational clinical research, might be considered. There is a perception that the training centres are lagging behind in the acquisition of new technologies in surgery. Efforts are required to maintain these necessary areas of training in the academic institutions. The debate regarding private/public co-operation in surgical training should be re-opened, especially in light of the proposed National Health System for SA in which some form of amalgamation of the two systems is mooted.

\section{REFERENCES}

1. Chopra M, Lawn JE, Sanders D, et al. Achieving the health Millennium Development Goals for South Africa: Challenges and priorities. Lancet 2009;374(9694):1023-1031. [http://dx.doi.org/10.1016/S0140-6736(09)61122-3]

2. Yeo H, Viola K, Berg D, et al. Attitudes, training experiences, and professional expectations of US general surgery residents. JAMA 2009;302(12):1301-1308. [http:// dx.doi.org/10.1001/jama.2009.1386]

3. Gabram SGA, Hoenig J, Schroeder JW, et al. What are the primary concerns of recently graduated surgeons and how do they differ from those of the residency training years? Arch Surg 2001;136(10):1109-1114. [http://dx.doi.org/10.1001/archsurg.136.10.1109]

4. Degiannis E, Oettle GJ, Smith MD, et al. Surgical education in South Africa. World J Surg 2009;33(2):170-173. [http://dx.doi.org/10.1007/s00268-008-9815-2]

5. Bornman PC, Krige JE, Terblanche J, et al. Surgery in South Africa. Arch Surg 1996;13(1):6-12. [http://dx.doi.org/10.1001/archsurg.1996.01430130008001]

6. Apostolou C, Panieri E. National survey of surgeons' attitudes to laparoscopic surgical training in South Africa. S Afr J Surg 2007;45(3):86-90.

7. Benatar SR. Health care reform in the new South Africa. NEngl J Med 1997;336(12):891895. [http://dx.doi.org/10.1056/NEJM199703203361224]

8. Sachdeva AK, Bell RH, Britt LD, et al. National efforts to reform residency education in surgery. Acad Med 2007;82(12):1200-1210. [http://dx.doi.org/10.1097/ ACM.0b013e318159e052]

9. Satiani B. Business knowledge in surgeons. Am J Surg 2004;188(1):13-16. [http://dx.doi. org/10.1016/j.amjsurg.2003.12.056]

10. Jones K, Lebron RA, Mangram A, et al. Practice management education during surgical residency. Am J Surg 2008;196(6):878-881. [http://dx.doi.org/10.1016/j. amjsurg.2008.08.008]

11. Debas HT, Bass BL, Brennan MF, et al. American Surgical Association Blue Ribbon Committee report on surgical education: 2004. Ann Surg 2005;241(1):1-8. [http:// dx.doi.org/10.1097/01.sla.0000150066.83563.52] 